\title{
Do Recommendations for the Management of Hypertension Improve Cardiovascular Outcome? The Canadian Experience
}

\author{
Peter Bolli ${ }^{1}$ and Norm R. C. Campbell ${ }^{2}$ \\ ${ }^{1}$ Ambulatory Internal Medicine Teaching Clinic, Department of Medicine, McMaster University, 80 King Street, Suite 2, \\ Street Catharines (ON), Canada L2R $7 G 1$ \\ ${ }^{2}$ Departments of Medicine, Community Health Sciences and Physiology and Pharmacology, University of Calgary, Canada
}

Correspondence should be addressed to Peter Bolli, pbolli@xenomix.com

Received 13 April 2011; Accepted 22 September 2011

Academic Editor: Zafar Israili

Copyright ( $) 2011$ P. Bolli and N. R. C. Campbell. This is an open access article distributed under the Creative Commons Attribution License, which permits unrestricted use, distribution, and reproduction in any medium, provided the original work is properly cited.

\begin{abstract}
The Canadian Hypertension Education Program (CHEP) was established in 1999 as a response to the result of a national survey that showed that a high percentage of Canadians were unaware of having hypertension with only $13 \%$ of those treated for hypertension having their blood pressure controlled. The CHEP formulates yearly recommendations based on published evidence. A repeat survey in 2006 showed that the percentage of treated hypertensive patients with the blood pressure controlled had risen to $65.7 \%$. Over the first decade of the existence of the CHEP, the number of prescriptions for antihypertensive medications had increased by $84.4 \%$ associated with a significant greater decline in the yearly mortality from stroke, heart failure and myocardial infarction and a significant decrease in the hospitalization for stroke and heart failure. Therefore, the introduction of the CHEP and the yearly issue of updated recommendations resulted in a significant increase in the awareness, diagnosis and treatment of hypertension and in a significant reduction in stroke and cardiovascular morbidity and mortality. The CHEP model could serve as a template for its adoption to other regions or countries.
\end{abstract}

\section{Introduction}

Hypertension is still a major contributor to mortality worldwide [1], and it is estimated that there are 970 million hypertensives worldwide and it is predicted to increase to 1.56 billion in the year 2025 [2]. The risk for a fail or morbid cardiovascular or cerebral vascular event starts at the systolic blood pressure of $115 \mathrm{mmHg}$ and a diastolic blood pressure of $73 \mathrm{mmHg}$.

Therefore, it is not surprising that hypertension accounts for about $60 \%$ of strokes and $50 \%$ of heart failure [3]. Considering that lowering of systolic blood pressure by $10 \mathrm{mmHg}$ and diastolic blood pressure by $5 \mathrm{mmHg}$ reduces the relative risk for a coronary artery event by $23 \%$ and a stroke by $40 \%$, it follows that blood pressure is not optimally diagnosed and treated.

There can be several reasons for this lack of diagnosing and proper control of hypertension [4]. The major factors are patient related, for example, poor adherence to treatments, physician-related inertia to properly inform the public of the danger of hypertension and the failure of physicians to diagnose, initiate, and treat blood pressure to achieve the recommended blood pressure goals.

\section{The Canadian Situation}

A Canadian national survey conducted in Canada from 1985 to 1992 revealed that $45 \%$ of individuals were unaware of their blood pressure condition, $22 \%$ were aware of having hypertension but remained untreated, $21 \%$ were treated but not controlled, and only $13 \%$ had their blood pressure treated and controlled to target, that is, less than 140/ $90 \mathrm{mmHg}$ [5]. These results were disappointing particularly considering the easy access of Canadians to health care, but the Canadian results were similar to some European countries although better results were reported from the United States [6].

As a reaction to these results, the Canadian Hypertension Society established the Canadian Hypertension Education Program which issued the first recommendations for the 


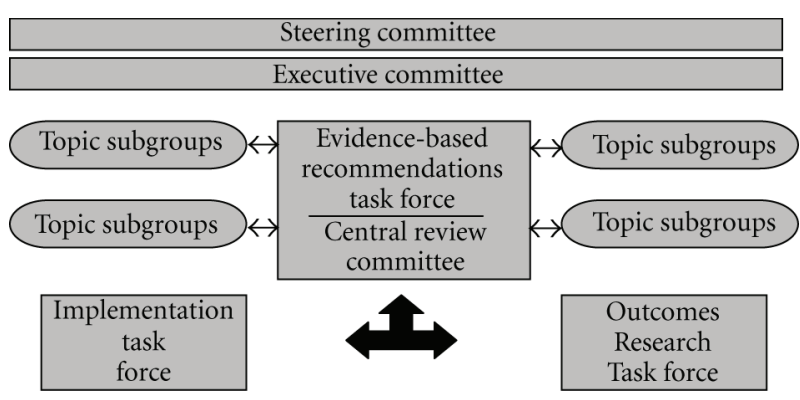

Figure 1: Organization of the Canadian Hypertension Education Program.

management of hypertension in 1999 [7]. The mandate of the Canadian Hypertension Education Program (CHEP) was to reduce the burden of cardiovascular disease in Canada through yearly updating evidence-based recommendations for the management of hypertension, implement the recommendations, regularly evaluate and revise the program, and assess the effect of the recommendations by measuring patient outcomes.

To fulfill these tasks, it required the establishment of a multidisciplinary structure as outlined in Figure 1 [8].

The CHEP is composed of the evidence-based task force which annually reviews and updates the recommendations according to new published information [8].

The implementation task force is responsible for the dissemination of the recommendations by members who have expertise in knowledge translation. Dissemination of information includes the yearly publication of the recommendations in the Canadian Journal of Cardiology which is freely available to every physician, distributing the recommendations to every practice, hospitals, public health system, the pharmaceutical industry, and local small group information meetings with physicians and nurses. Since public awareness is key to the success of improvement in hypertension management, a public education task force has developed information material for patients and the public at large through easy-to-understand pamphlets in several languages, articles in the lay press, public information meetings, and availability of a website (http://www.hypertension.ca/) [9, 10].

The Outcomes Research Task Force is responsible for evaluating and monitoring the effect of the CHEP activities on the public awareness and the management of hypertension at large. This is accomplished through a national surveillance system in collaboration with the Public Health Agency of Canada, the Canadian Institute for Health Research, the Heart and Stroke Foundation of Canada, the Canadian Stroke Network, provincial databases, and a number of other organizations [11]. The data collection includes physical measures and questionnaire surveys, morbidity and mortality data for hypertension, cardiovascular complications, and data on antihypertensive drug prescriptions. Questionnaire surveys are performed every two years to assess the prevalence of hypertension diagnosis and treatment. A national hypertension surveillance program has been initiated and has produced some initial results [11]. All this activity is overseen and directed by the executive and steering committees
(Figure 1). Gradually, a number of scientific organizations, health care professionals and public health organizations became involved in the effort to improve hypertension management in Canada.

\section{Effectiveness of the Canadian Hypertension Education Program}

A national survey which was completed in 1992 showed that almost $50 \%$ of Canadians were unaware of having hypertension, $22 \%$ who were diagnosed with hypertension were not treated, and of those treated, only 13\% had their blood pressure controlled below $140 / 90 \mathrm{mmHg}$ [5]. The survey was then repeated in 2006 which showed that the proportion of Canadians who were unaware of hypertension had decreased to $16.7 \%$ and those treated and had their blood pressure controlled had risen to $65.7 \%$ [12]. This improvement was associated with a significant $84.4 \%$ increase in the number of prescriptions for antihypertensive drugs [13-15]. There was also an increased use of 2 or more antihypertensive drugs [16]. The largest increase of medications occurred in thiazide diuretics and ace inhibitors, and the smallest increase occurred in beta blockers, consistent with the CHEP recommendations not to use beta blockers as a first-line drug in patients older than 65 years of age $[14,15]$. This was paralleled with an increase in hypertension-related physician office visits [14].

The improvement in the management of hypertension resulted in a significant reduction in cardiovascular events and stroke [13]. Since the inception of the CHEP in 1999, there was a significant greater yearly reduction in mortality due to stroke $-3 \%$, heart failure $-4.3 \%$, and $-2.1 \%$ for acute myocardial infarctions. Similarly, there was also a significant reduction in the number of hospitalizations for stroke $-1.6 \%$ and $-3.1 \%$ for heart failure, but the rate of decline in hospitalization for acute MI remained unchanged, the reason for which is not entirely clear. The decrease in mortality correlated with the increase in the prescription for antihypertensive drugs [13]. The average yearly reductions in mortality due to heart failure, stroke, and acute MI were significantly greater than for noncardiovascular disease deaths or cancer [17]. A recent Canadian population survey confirmed the high rates of treatment and control of hypertension [18].

At the end of the first decade of the existence of the CHEP, certain factors that became important for the sustainability of the CHEP process became apparent and may serve as a guide to implement such a program in other regions or countries [19]. It needs a critical number of experts in the field to reduce individual bias and influence in order to achieve an objective result which at the end should be dictated by up-to-date evidence forming the base of the recommendations and translating data from trials and scientific studies into practical and applicable recommendations. Before issued, consensus on the content on wording of the recommendations has to be achieved.

It also includes the participation of interdisciplinary health teams. In order to be applicable, recommendations should be revised yearly as new information becomes rapidly available. As the overseeing body, academic and government 
organizations are involved, which is an important factor for the integrity and credibility of the program. Although the members of the CHEP are all volunteers, certain costs have to be covered, and persistent financial support is important for the continuation of such a program.

\section{Acknowledgments}

The authors would like to thank Linda and Taralyn Shields for excellent secretarial work.

\section{References}

[1] A. Rodgers, P. Vaughan, T. Prentice, T. T. Edejer, and D. Evans, The World Health Report 2002, World Health Organization, Geneva, Switzerland, 2002.

[2] P. M. Kearney, M. Whelton, K. Reynolds, P. Muntner, P. K. Whelton, and J. He, "Global burden of hypertension: analysis of worldwide data," The Lancet, vol. 365, no. 9455, pp. 217223, 2005.

[3] C. M. M. Lawes, S. Vander der Hoorn, M. R. Law, P. Elliott, S. MacMahon, and A. Rodgers, "Blood pressure and the global burden of disease 2000. Part II: estimates of attributable burden," Journal of Hypertension, vol. 24, no. 3, pp. 423-430, 2006.

[4] D. R. Berlowitz, A. S. Ash, E. C. Hickey et al., "Inadequate management of blood pressure in a hypertensive population," New England Journal of Medicine, vol. 339, no. 27, pp. 19571963, 1998.

[5] M. R. Joffres, P. Ghadirian, J. G. Fodor, A. Petrasovits, A. Chockalingam, and P. Hamet, "Awareness, treatment, and control of hypertension in Canada," American Journal of Hypertension, vol. 10, no. 10, pp. 1097-1102, 1997.

[6] K. Wolf-Maier, R. S. Cooper, J. R. Banegas et al., "Hypertension prevalence and blood pressure levels in 6 European countries, Canada, and the United States," Journal of the American Medical Association, vol. 289, no. 18, pp. 2363-2369, 2003.

[7] R. D. Feldman, N. Campbell, P. Larochelle et al., "1999 Canadian recommendations for the management of hypertension," Canadian Medical Association Journal, vol. 161, supplement 12, pp. S1-S17, 1999.

[8] K. B. Zarnke, N. R. C. Campbell, F. A. McAlister, and M. Levine, "A novel process for updating recommendations for managing hypertension: rationale and methods," Canadian Journal of Cardiology, vol. 16, no. 9, pp. 1094-1102, 2000.

[9] D. Drouin, N. R. C. Campbell, and J. Kaczorowski, "Implementation of recommendations on hypertension: the Canadian Hypertension Education Program," Canadian Journal of Cardiology, vol. 22, no. 7, pp. 595-598, 2006.

[10] N. R. C. Campbell, R. Petrella, and J. Kaczorowski, "Public education on hypertension: a new initiative to improve the prevention, treatment and control of hypertension in Canada," Canadian Journal of Cardiology, vol. 22, no. 7, pp. 599-603, 2006.

[11] N. R. C. Campbell and J. Onysko, "The outcomes research task force and the Canadian Hypertension Education Program," Canadian Journal of Cardiology, vol. 22, no. 7, pp. 556-558, 2006.

[12] F. Leenen, J. Dumais, N. McInnis et al., "2006 ontario survey on the prevalence and control of hypertension (ON-BP)," Canadian Medical Association Journal, vol. 178, pp. 1441$1449,2008$.
[13] N. R. C. Campbell, R. Brant, H. Johansen et al., "Increases in antihypertensive prescriptions and reductions in cardiovascular events in Canada," Hypertension, vol. 53, no. 2, pp. 128$134,2009$.

[14] B. R. Hemmelgarn, G. Chen, R. Walker et al., "Trends in antihypertensive drug prescriptions and physician visits in Canada between 1996 and 2006," Canadian Journal of Cardiology, vol. 24, no. 6, pp. 507-512, 2008.

[15] N. R. C. Campbell, F. A. McAlister, R. Brant et al., "Temporal trends in antihypertensive drug prescriptions in Canada before and after introduction of the Canadian hypertension education program," Journal of Hypertension, vol. 21, no. 8, pp. 1591-1597, 2003.

[16] C. I. Neutel and N. R. C. Campbell, "Antihypertensive medication use by recently diagnosed hypertensive Canadians," Canadian Journal of Cardiology, vol. 23, no. 7, pp. 561-565, 2007.

[17] F. A. McAlister, R. D. Feldman, K. Wyard, R. Brant, and N. R. C. Campbell, "The impact of the Canadian Hypertension Education Programme in its first decade," European Heart Journal, vol. 30, no. 12, pp. 1434-1439, 2009.

[18] K. Wilkins, N. R. Campbell, M. Joffres et al., "Blood pressure in Canadian adults," Health Reports, vol. 21, no. 1, pp. 37-46, 2010.

[19] N. R. C. Campbell and T. Sheldon, "The canadian effort to prevent and control hypertension: can other countries adopt canadian strategies?" Current Opinion in Cardiology, vol. 25, no. 4, pp. 366-372, 2010. 


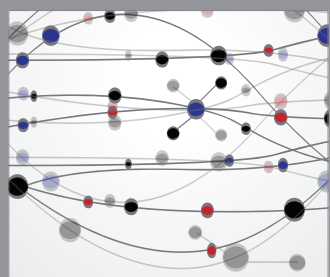

The Scientific World Journal
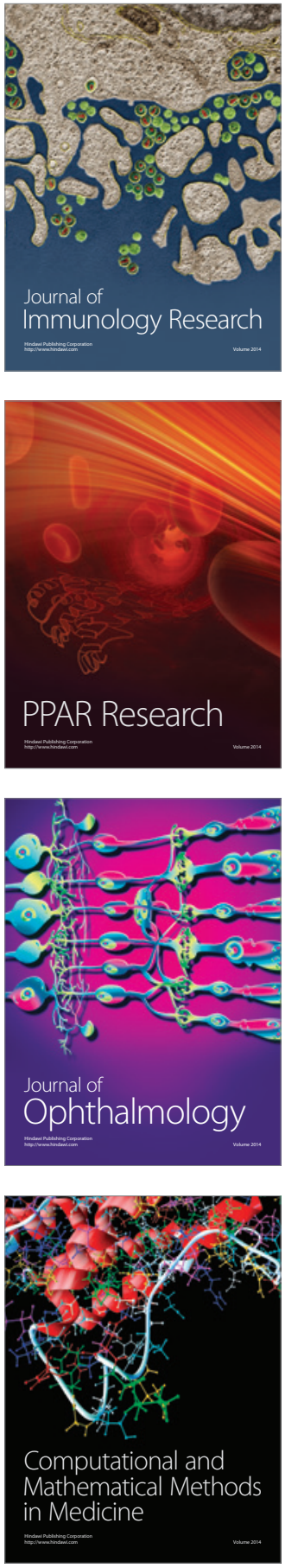

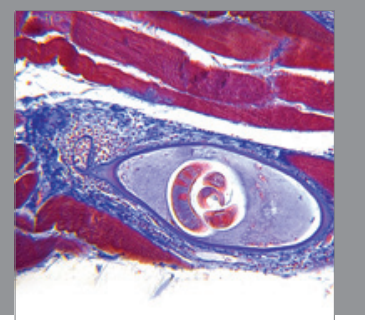

Gastroenterology

Research and Practice
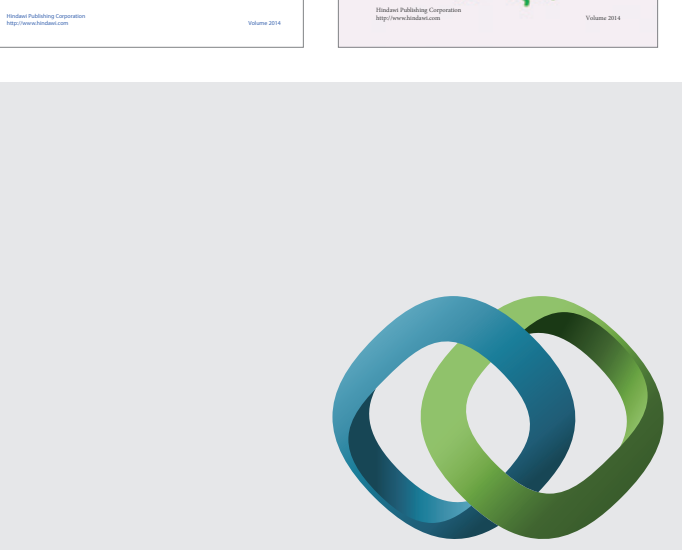

\section{Hindawi}

Submit your manuscripts at

http://www.hindawi.com
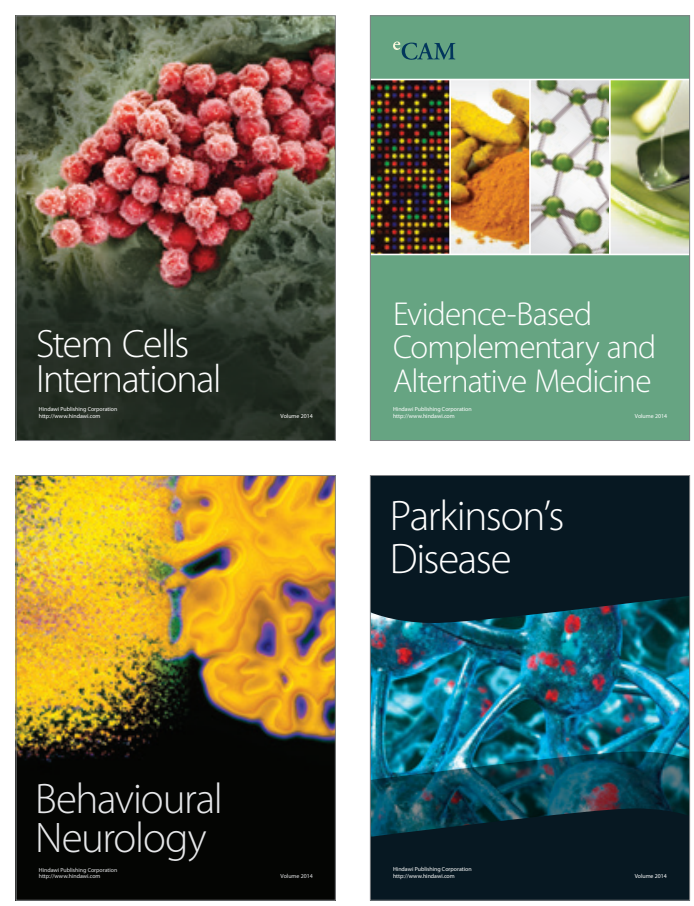

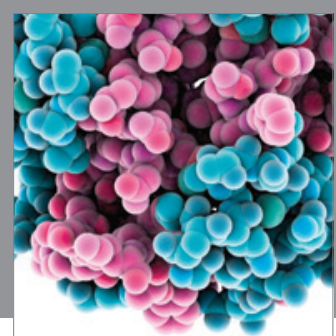

Journal of
Diabetes Research

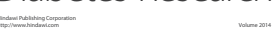

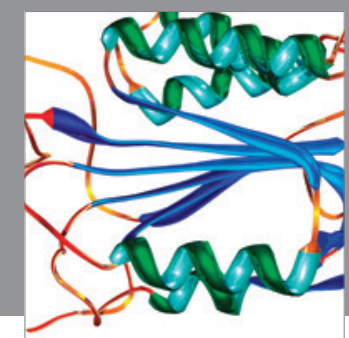

Disease Markers
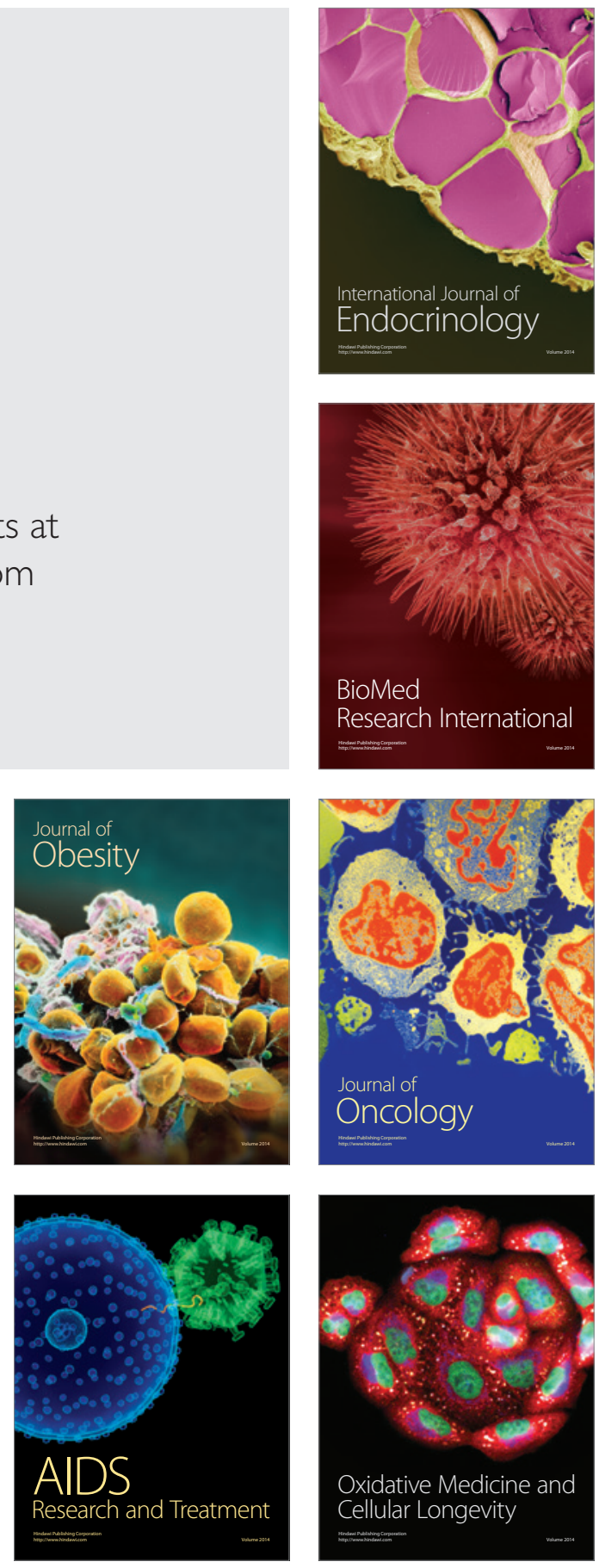